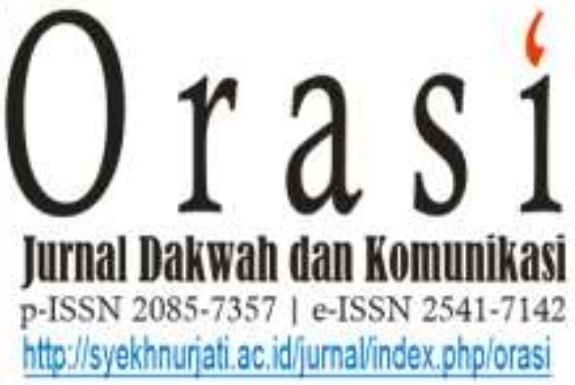

Volume 12 No. 1 Juli 2021

\title{
TREN KONTEN DAKWAH DIGITAL OLEH CONTENT CREATOR MILENIAL MELALUI MEDIA SOSIAL TIKTOK DI ERA PANDEMI COVID-19
}

\section{TRENDS OF DIGITAL DA'WAH BY MILLENIAL CONTENT CREATOR THROUGH TIKTOK SOCIAL MEDIA IN THE COVID-19 PANDEMIC ERA}

\author{
Dessy Kushardiyanti1,a), Zaenal Mutaqin'2,b), dan \\ Aulia Sholichah Iman Nurchotimah ${ }^{3, c}$ ) \\ ${ }^{123}$ Jurusan Komunikasi dan Penyiaran Islam, IAIN Syekh Nurjati Cirebon \\ Jl. Perjuangan By Pass Sunyaragi Cirebon \\ ${ }^{a}$ e-mail: dessykushardiyanti@syekhnurjati.ac.id

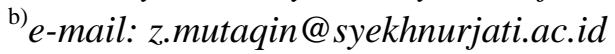 \\ ${ }^{\text {c) }}$-mail: auliasin@syekhnurjati.ac.id
}

\begin{abstract}
ABSTRAK
New media merupakan media komunikasi digital akibat perkembangan internet yang melibatkan banyak audiens, lebih interaktif, akses informasi lebih cepat dan lebih mudah bagi penggunanya. TikTok merupakan salah satu sosial media daring dan juga bentuk konkrit dari new media. Perkembangan new media tidak dapat dipungkiri juga menuntut para pendakwah dalam menguasai teknis dalam penyampaian ilmu keagamaan. Penelitian ini menyusuri dan menganalisis konten (content Analysis) pada sosial media TikTok untuk melihat rangkaian strategi konten dari beberapa content creator dakwah. Penelitian ini menggunakan metode penelitian kualitatif deskriptif dengan analisis konten di masing-masing content creator dakwah terlibat. Hasil penelitian menyebutkan peran sosial media ditinjau dari analisis isi memberikan dampak terhadap engagement berupa like, view, dan keterlibatan pengguna TikTok dalam konten dakwah. Konten yang dibuat dari masing-masing content creator ditinjau dari materi dakwah, teknik penyampaian, rata-rata unggahan tiap bulan dan penggunaan hashtag populer dari beberapa content creator menunjukan secara teknis dalam pembuatannya masing-masing memiliki ciri khasnya tersendiri sehingga dapat diingat oleh pengikutnya. Penelitian ini dapat menjadi pertimbangan dan
\end{abstract}


rujukan teknis bagi para milenial hingga para da'i untuk ikut terlibat dalam penyampaian dakwah melalui media sosial yang kini banyak dijadikan tren selama pandemi Covid-19.

Kata Kunci: Analisis Konten, Dakwah, TikTok, Engagement, Content Creator

\section{ABSTRACT}

New media are digital communication media due to the development of the internet which involves many audiences, are more interactive, and of which access information is faster and easier for users. TikTok is one of the online social media and also a concrete form of new media. The development of new media cannot be avoided, which requires the preachers ( $d a^{\prime}$ is) to master the techniques in delivering religious knowledge. This study traced and analysed content on TikTok social media to see a series of content strategies from several da'wah content creators. This study used descriptive qualitative research methods with content analysis on every da'wah content of the creators involved. The results of the study state that the role of social media in terms of content analysis has an impact on engagement in the form of likes, views, and involvement of TikTok users in da'wah content. The contents created from each content creator in terms of da'wah material, delivery techniques, average uploads per month and the use of popular hashtags from several content creators show that in the content making process each creator technically has his/her own characteristics which can be remembered by the followers. This research can be a consideration and a technical reference for millennials and da'is to be involved in delivering da'wah through social media which are now widely used as a trend during the Covid-19 pandemic.

Keywords: Content Analysis, Da'wah, TikTok, Engagement, ContentCreator

\section{Pendahuluan}

Penggunaan media sosial telah menjadi kebutuhan bagi masyarakat di Indonesia, tak terkecuali generasi milenial, selain untuk pemenuhan kebutuhan informasi sehari-hari, media sosial juga kerap digunakan sebagai wadah berkreatifitas dalam membuat kontenkonten yang menarik perhatian para penggunanya. Kenaikan pengguna media sosial meningkat dari tahun sebelumnya, dilansir dari laporan terbaru We Are Social menyebutkan pada tahun 2020 ada 175,4 juta pengguna internet di Indonesia. Mengalami kenaikan 17\% dari tahun 2019. Di era pandemi Covid-19, dimana terdapat kebijakan Pemerintah bagi masyarakat untuk melalukan social distancing atau PSBB, maka masyarakat akan berusaha mencari aktivitas mengisi waktu luang di rumah, salah satunya dengan bermedia sosial, salah satu media sosial yang hingga saat ini menjadi tren di kalangan milenial yaitu TikTok. Beragam media sosial yang banyak digunakan selama aktifitas di rumah yaitu youtube, whatsapp, facebook, instagram, tiktok, line, twitter, reddit, pinterest dan tumblr (Widyananda, 2020).

Beragam konten berformat video dan musik disajikan oleh para content creator di TikTok, dari konten hiburan, edukasi, informasi

Orasi: Jurnal Dakwah dan Komunikasi | Volume 12, No. 1, Juli 2021 
hingga dakwah dapat dilakukan. Para content creator tentu lebih leluasa dalam membuat konten berdurasi 15-60 detik sesuai ciri khas mereka. Dan bagi para pengguna TikTok, kemudahan akses dan segmentasi video dapat dipilih sesuai minat dan ketertarikan terhadap konten tertentu. Memasuki abad informasi, menjadikan sumber daya informasi dari old media (media lama) menuju ke new media (media baru) (Haryatmoko, 2011).

Perkembangan komunikasi dakwah mengikuti perkembangan teknologi menuntut para penyampai dakwah agar dapat memperluas persebaran dakwah bagi masyarakat Indonesia, salah satunya melalui media sosial. Di era pandemi Covid-19, penggunaan media sosial menjadi pilihan karena tingkat kemudahan aksesbilitasnya bagi para pengguna. Dengan demikian diharapkan optimalisasi dakwah dapat lebih maksimal dari segi waktu, jarak, proses dan biaya (Habibi, 2018). Selain itu, konsep dakwah digital melalui media sosial TikTok ini juga merupakan terusan dari perkembangan media kontemporer yang memiliki konsep yang menarik dengan menggunakan berbagai teknik penyampaian audio visual untuk berdakwah sehingga membuat kuantitas engagement yang tinggi dari berbagai target pengguna media sosial (Wibowo, 2019).

Pengunaan media sosial TikTok sebagai salah satu media baru di media massa tentu menjadi rujukan yang diminati sebagai referensi ilmu keagamaan. Hal ini berkaitan dengan dakwah kontemporer dengan menggunakan fasilitas modern yang diharapkan dapat mendorong umat Islam pada perubahan positif dalam sistem penyebaran dakwah yang kini sedang dikembangkan oleh para ulama dan da'i di Indonesia (Fahrurrozi 2017). tren dakwah digital menunjukan bahwa di era globalisasi, seorang da'i atau penyampai dakwah dituntut bukan hanya untuk cakap dalam wawasan keagamaan serta dakwah, namun juga hal teknis dalam penyebaran informasi dakwah melalui teknologi informasi dan komunikasi. Tercapainya kemampuan seorang da'i dalam hal teknis tersebut tentu dapat menjadi pendukung persebaran dakwah yang signifikan kepada masyarakat, hal ini sesuai dengan riset mengenai dakwah digital yang dilakukan oleh (Muhaemin, 2017).

TikTok sebagai salah satu media sosial populer dimana semua masyarakat terutama milenial memiliki akses internet dan preferensi penggunaan media maka sangat berpotensi untuk dijadikan target dakwah, selain itu kuantitas mad'u yang lebih banyak jika dibanding media lama sehingga diharapkan akan sangat bermanfaat (Qadaruddin, 2019). Termasuk dalam lingkungan santri, penyebaran dakwah melalui media sosial TikTok juga direkomendasikan oleh salah satu admin ala Nahdlatul ulama selain agar tidak ketinggalan zaman, para santri milenial juga diharapkan mampu menangkap dan memainkan peluang narasi yang ada dalam ruang dakwah digital (Jailani 2020) 
Adanya kesempatan dakwah digital membuat beberapa content creator islami menjadi sangat populer di kalangan pengguna TikTok, mayoritas konten video yang dibuat bertemakan kajian islam dan juga bertujuan untuk mendapat profit dari karya yang dihadirkan di TikTok. Para content creator dakwah ini merupakan representasi dari generasi milenial yang memanfaatkan keberadaan media baru dengan baik. Hasil yang diperoleh dari penelusuran konten yang telah dibuat oleh content creator dakwah menunjukan keberhasilan dalam strategi pemanfaatan TikTok sebagai media dakwah digital.

Melihat latar belakang di atas menarik untuk ditelusuri bagaimana strategi konten melalui pemanfaatan media sosial TikTok oleh content creator dalam melakukan gerakan dakwah digital yang ditujukan kepada pengguna dalam menyebarkan ilmu keagamaan.

\section{Metodologi Penelitian}

Penelitian ini menggunakan metode penelitian kualitatif deskriptif bertujuan untuk menggambarkan data dengan kata-kata atau kalimat yang diklasifikasikan berdasarkan kategori pemilihan sehingga memperoleh kesimpulan sesuai tujuan penelitian. Pernyataan tersebut dikemukakan oleh (Arikunto dalam Ayuningtyas, 2020). Model penelitian kualitatif berfokus pada analisis isi (content Analysist) menggunakan pendekatan dari (Mayring, 2019). Media komunikasi dan sumber data utama adalah TikTok. Peneliti melakukan beberapa tahapan untuk melakukan analisis isi, yaitu:

1) Pengelompokan beberapa akun content creator relevan dengan dakwah digital sebagai unit penelitian

2) Melakukan pengunduhan konten pada TikTok, berupa video yang berkaitan dengan pengelolaan konten dakwah dengan menganalisis video tersebut.

3) Pengumpulan akun diberlakukan berdasarkan content creator populer, melihat engagement yang ditinjau dari jumlah followerss, total view, dan total like

4) Melakukan klasifikasi analisis dilihat dari beberapa komponen, seperti:

a. Call to Action dan berupa tulisan persuasi pada konten video

b. Pengelolaan konten video berupa aktivitas merespon komentar, materi dakwah yang disampaikan, dan durasi post

c. Penggunaan hashtag pada konten video oleh content creator

Pemberlakuan metode penelitian menggunakan analisis isi pada tikTok untuk melihat seberapa jauh TikTok sebagai new media dapat menggiring, meyakinkan followers TikTok melihat seberapa berkembangnya dan tumbuhnya tren dakwah digital.

\section{Hasil dan Pembahasan}

\subsection{New Media}

New media merupakan personifikasi dari internet. Dewasa ini, aktivitas manusia tidak bisa terlepas dari teknologi informasi dengan akses 
dan kecepatan yang memumpuni. Hadirnya internet membuat proses transformasi terhadap akses informasi menjadi berbeda dan fungsional apabila dibandingkan dengan media terdahulu, seperti televisi, radio, media cetak, dan sebagainya. Ciri khas dari new media adalah penyediaan konten dengan berbagai jenis, baik teks, foto, video, bersifat informatif, interaktif sehingga dapat menghasilkan ruang-ruang interaksi, forum untuk sesama pengguna media tersebut.

McQuail dalam Norhabiba dan Putri (2018) menyebutkan ciri khas new media adalah interdependensi (saling keterhubungan), aksesibilitas tinggi antara pengirim dan penerima pesan, kegunaan yang beragam, dan adanya interaktivitas didalamnya. Tingkat interaksi new media mengacu pada rasio saling respon yang cepat, tingkat sosialisasi bersifat individual, karena adanya instrumen atau gawai yang terhubung dengan internet, seperti telepon genggam, tablet, komputer, laptop dan sebagainya. Menimbulkan kesenangan tinggi karena dapat mengakses segala informasi dengan tingkat privasi tinggi.

(Littlejohn dalam Indrawan, Efriza, dan Ilmar, 2020) menyebutkan bahwa new media sebagai bentuk komunikasi yang menggabungkan 3 komponen, yaitu teknologi informasi dan komputasi, jaringan komunikasi, dan digitalasi media dan informasi berupa konten. Selain itu, Power dan Little John menyebutkan juga definisi lainnya yaitu periodisasi dari komunikasi baru yang interaksi melalui media teknologi dan jaringan komunikasi, khususnya media internet, dimana dapat mengubah sebuah tatanan masyarakat. Penjelasan khusus dari new media adalah kapasitas dimiliki oleh media tersebut adalah kekuatan yang membawa perubahan dalam masyarakat.

\subsection{Media Sosial TikTok}

Media sosial TikTok kian lama menjadi media sosial yang mendatangkan banyak konten viral di tengah masyarakat Indonesia. Adanya bencana global Covid-19 menjadikan TikTok semakin ramai pengguna, baik pembuat konten atau sekedar sebagai penikmat konten. Awal mula munculnya TikTok di tahun 2016 diinsiasi oleh perusahaan asal China, ByteDanc dengan nama awal aplikasi Douyin, hanya dalam waktu 1 tahun mampu mencapai 100 juta pengguna dengan total tayangan video sebanyak 1 miliar setiap harinya (Kumparan, 2020).

Namun, di tahun 2018 TikTok menuai pro kontra di tengah masyarakat Indonesia karena beredarnya video-video SARA dan tidak pantas untuk ditonton oleh masyarakat Indonesia, hingga akhirnya TikTok sempat diblokir oleh Kementerian Komunikasi dan Informatika di tahun 2018, dikarenakan sekitar 3000 petisi masyarakat Indonesia menganggap konten tiktok negatif seperti pelanggaran asusila, pornografi hingga pelecehan agama. Bukan hanya Kominfo, Kementerian Pemberdayaan Perempuan dan Perlindungan Anak serta Komisi Perlindungan Anak Indonesia juga mendapat laporan yang sama (daon001, 2018). 
Dalam rangka mendukung aktivitas para content creator dalam mengembangkan kontenkontennya di TikTok, maka TikTok menawarkan beragam fitur yang menarik untuk dicoba, terutama untuk menjaring penonton sesuai dengan segmentasi konten video yang dibuat, diantaranya:

1. Tambahan musik sebagai background music video

Salah satu hal yang dapat menarik penonton di TikTok adalah jenis dan genre musik yang digunakan sebagai music background, para content creator dapat menggunakan musik yang sedang tren sebagai imbuhan pada background video yang dibuat.

2. Fitur pengubah suara

Salah satu yang menarik perhatian para penonton adalah suara yang dihasilkan oleh para content creator untuk menyampaikan narasi atau cerita yang dibawakan dalam video, maka fitur pengubah suara menjadi pertimbangan agar suara dapat didengar dengan baik dan sesuai dengan substansi konten yang dibuat.

3. Ketersediaan stiker dan efek

Konsep konten video akan lebih menarik ditonton dengan penggunaan efek video dan filter yang tepat, seperti dalam konten dakwah, maka sebagai penunjang content creator dapat menambah efek menggunakan sorban atau stiker seolah-olah sedang menyampaikan kajian islami di mimbar dakwah. Hal ini akan menambah variasi konten video yang dibuat.

4. Filter

Tone dan rona isi dari konten akan menjadi lebih menarik jika content creator memilih filter yang tepat. Seperti saat menyampaikan konten dakwah antara penghuni surga dan neraka, maka dapat menggunakan filter cerah untuk penghuni surga, dan filter seram untuk penghuni neraka.

5. Timer

Tidak semua content creator dibantu oleh orang lain untuk membantu mengatur timing video, maka fitur timer di sini akan sangat membantu untuk content creator melakukan proses pengambilan video sendiri (Budiansyah 2020).

Setelah video yang dibuat selesai, file video dapat diunggah ke akun TikTok, dengan teks tambahan dan tagar, yang mendorong pengikut akun untuk menerima pemberitahuan bahwa video akun baru yang diikuti tersedia untuk menonton (Hayes et al., 2020).

Di tahun 2020, dimana masa PSBB masih berlangsung di Indonesia, TikTok kembali tren di semua kalangan usia, tak terkecuali gen $\mathrm{Y}$ yaitu milenial dan gen $\mathrm{Z}$ dengan rentang usia 14-24 tahun (Donny Eryastha dalam Rakhmayanti, 2020). Konten TikTok pun semakin beragam dan hampir semua segmentasi video dapat dinikmati oleh para pengguna, salah satunya adalah segmentasi 
video dakwah islami yang kian populer dengan ciri khas masing-masing content creator, penyajian materi yang ringan dan dapat dinikmati oleh para pengguna TikTok kini menjadi budaya populer. tren yang diciptakan dalam budaya populer dapat menyesuaikan dengan kondisi dan dinikmati oleh audiens lebih luas dan jika tidak dapat beradaptasi maka akan tergantikan dengan budaya populer lain, itulah mengapa budaya populer keberadaannya mengikuti waktu selera audiens, profibilitas atau kepentingan dari beberapa pihak, efeknya dapat menciptakan gangguan dan kesenangan (Mahanani, 2015).
Menurut (Wiederhold, 2020) selama masa pandemi Covid-19 seseorang akan cenderung bermedia sosial atas kebutuhan untuk mencari informasi dan hiburan. Kenaikan pengguna media sosial, khususnya TikTok di Indonesia meningkat hingga $20 \%$ selama masa pandemi dari pada biasanya, mayoritas pengguna membuat konten edukasi, makanan, hingga fesyen di aplikasi tersebut (Annur, 2020). Mayoritas generasi milenial dengan rentang usia 20-39, dimana menurut hasil penelitian oleh (Pew Research Center dalam Hikmawati dan Farida, 2021) menyebutkan bahwa generasi milenial merupakan generasi yang paham akan teknologi, generasi milenial identik dengan kebiasaannya yang tidak pernah lepas dengan teknologi termasuk dalam kebutuhannya mencari informasi.

\subsection{Awal mula munculnya tren dakwah di TikTok}

Dakwah adalah usaha untuk meningkatkan pemahaman dalam ilmu agama yang dapat menggerakan umat baik dari pandangan, sikap batin dan hidup, mengubah perilaku umat dari yang sebelumnya tidak sesuai dengan ajaran Islam menjadi sesuai tuntunan syariat Islam agar memperoleh kebahagiaan hidup di dunia dan akhirat (Amin, 2008).

Melihat tren dakwah di media sosial TikTok maka teringat dengan ucapan Sayyidil Habib Umar:

"Dakwah itu luas ( bukan hanya melalui satu cara seperti ceramah saja) tidak akan bisa memahami dakwah kecuali mereka yang memiliki pemahaman yang luas" (Kholilie 2020).

Transformasi dakwah oleh Rosululloh merupakan kegiatan sosial yang berhubungan dengan aktivitas masyarakat pada umumnya yang nantinya berorientasi pada upaya dalam menciptakan masyarakat ideal, yang memiliki dasar keimanan yang kuat, ketauhidan utuh dan amalan yang mulia (Rustandi and Sahidin, 2019).

Wabah Covid-19 telah memberikan banyak pelajaran bagi umat manusia di bumi, segala aktivitas terbatas termasuk dalam hal melangsungkan ibadah dan dakwah. Penggunaan teknologi komunikasi saja tidak cukup, jika tanpa peran serta penggunanya dalam menciptakan strategi penggunaan teknologi komunikasi yang tepat melalui media yang ada. Di sinilah peran milenial diperlukan, milenial 
sebagai generasi "melek teknologi" maka perlu paham bagaimana strategi penggunaan teknologi komunikasi yang tepat agar penyampaian pesan dapat diterima dengan baik oleh penerimanya.

Dakwah membawa pesan yang baik bagi penerimanya, maka penting diperhatikan metode penyampaian yang tepat dan dapat menjangkau umat yang lebih luas. Dari waktu ke waktu metode dakwah semakin berkembang jauh lebih baik, dari metode tradisional berupa seni tradisi islami yang dipentaskan dalam bentuk hiburan dan komunikatif hingga metode modern yaitu dengan menggunakan teknologi komunikasi yang juga semakin berkembang pesat, hingga kini kita kenal dengan istilah new media. Tersedia banyak pilihan bagi seorang pendakwah untuk mentransfer pesannya, seperti melalui $\mathrm{TV}$, radio, hingga media sosial yang menjadi bagian dari internet (Aziz, 2019).

tren dakwah digital semakin banyak diminati oleh para pendakwah milenial, salah satunya melalui media sosial. Aksesbilitas yang mudah dan dapat menjangkau penerima pesan lebih banyak menjadi keuntungan yang sangat dipertimbangkan, pesan yang disampaikanpun jauh lebih variatif dengan beragam format konten baik teks, foto, video. Begitu juga bagi objek dakwah, pesan-pesan dakwah akan sampai pada media yang dipilih, tanpa harus bertemu dengan pedakwah sebagai narasumber, hal ini juga dapat meminimalkan biaya dan energi untuk menerima pesan dakwah (Pardianto, 2013).
Hakekatnya, islam perlu dalam mengikuti perkembangan zaman agar tidak ditinggalkan oleh pengikutnya, penggunaan media kontemporer bahkan membantu kita sebagai generasi penerus islam dalam melanjutkan misi dakwah beliau. Kemunculan tren dakwah di TikTok merupakan keberlanjutan dari arus perkembangan dakwah kontemprer salah satunya melalui media sosial. Penggunaan media sosial TikTok telah menjadi media rujukan oleh berbagai kalangan dari masyarakat biasa, milenial bahkan hingga kalangan akademisi.

Berdasarkan hasil penelitian terbaru (Hikmawati dan Farida, 2021) bahkan menunjukan penggunaan media sosial TikTok sebagai media dakwah telah dikembangkan oleh sebagian dosen di IAIN Sunan Kalijogo Malang dan mendapat respon positif melalui aktualisasi pesan-pesan pendidikan keagamaan yang berhaluan ahlusunnah wal Jama'ah sampai dapat diterima oleh berbagai kaalangan yaitu anakanak, remaja, dewasa, hingga orang tua.

Dengan segala kelengkapan fitur di Aplikasi TikTok salah satunya dalam hal editing video dan menjangkau audiens maka apa salahnya jika TikTok digunakan sebagai ruang berkreatifitas sekaligus berdakwah. Salah satu content creator islami yang populer karena banyak diperbincangan di berbagai media massa dan tak jarang muncul pada rekomendasi 'For Your Page' para pengguna TikTok yaitu Zahra Hashimee melalui akun TikTok-nya yaitu @muslimthicc. Banyak pengguna TikTok yang 
tidak asing dengan hijabers satu ini, walaupun Ia tinggal di Newyork dengan intensitas penduduk muslim yang tidak terlalu banyak. Zahra Hashimee berhasil menjadi terkenal dengan keviralannya dalam diskusi agama islam bersama teman-temannya.

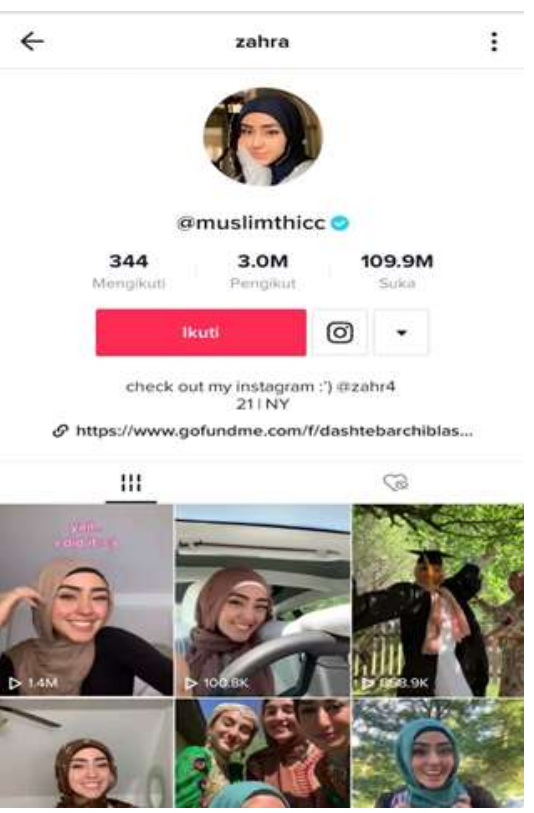

Gambar 1. Akun TikTok @ muslimthicc milik Zahra Hashimee

Dalam kurun waktu 1 tahun saja selama tahun 2019, Ia berhasil menjaring 1,8 juta pengikutnya hingga saat ini berhasil meraih 3 juta followerss dengan total view sebanyak 109 juta+ viewer. Melalui konten yang ia bagikan setiap harinya dapat menjangkau engagement yang baik dengan para pengikutnya, termasuk pengikut di Indonesia.

Zahra Hashimee kemudian menjadi inspirasi bagi para pendakwah milenial di Indonesia untuk turut dalam menyebarkan ilmu keagamaan melalui media sosial TikTok dengan caranya masing-masing. Berbagai teknik penyampaian dilakukan oleh Zahra Hashime seperti monolog dengan dirinya sendiri, menjelaskan secara audio visual terkait materi dakwah yang dihubungkan dengan situasi yang sedang tren, pembawaannya yang ceria membuat pengikutnya tidak pernah merasa bosan tiap kali menonton konten video dakwahnya di TikTok.

Hal inilah yang kemudian menjadi penting bagi para content creator, walau semua konten pasti ada segmentasinya sendiri-sendiri, namun perlu diingat bahwa dampak dari konten yang dibagikan salah satunya yaitu pada metriks sosial media berupa like, komentar dan ditambah view jika media sosial yang digunakan adalah TikTok (Frick, 2013).

Kini telah banyak bermunculan para content creator yang berkontribusi dalam upaya penyebaran dakwah kekinian salah satunya melalui media sosial TikTok. Jika telusuri dari penggunaan hashtag saja sudah banyak konten yang diunggah diluar hanya dari content creator populer di TikTok, berikut data hashtag berkaitan dengan konten dakwah di media sosial TikTok:

Tabel 1. Penelusuran top hashtag berkaitan dengan dakwah di TikTok

\begin{tabular}{ccc}
\hline No & Hashtag & Total view \\
\hline 1 & @ dakwah & $1.2+$ Miliar \\
\hline 2 & @ tiktokdakwah & $197.8+$ juta \\
\hline 3 & @ dakwahtiktok & $649.9+$ Juta \\
\hline 4 & @ tiktokdakwahislam & $19.9+$ juta \\
\hline 5 & @ dakwahtiktokvirall & $6.6+$ juta \\
\hline 6 & @ tiktokdakwahislamiah & $1.4+$ juta \\
\hline
\end{tabular}




\subsection{Penelusuran Konten Dakwah Oleh content creator TikTok}

Peneliti telah menelusuri eksistensi content creator berkaitan dengan aktivitas dakwah yang dilakukan di media sosial TikTok. Beragam materi dakwah telah disampaikan oleh masing-masing content creator dengan ciri khas yang mampu mengundang atensi dari para pengguna TikTok. Data mengenai content creator terkait konten dakwah, beserta akun TikTok yang sesuai dengan kriteria dituliskan dalam tabel sebagai berikut:

Tabel 2. Penelusuran Akun contentcreator Dakwah di TikTok tehirtung hingga bulan Mei 2021 (Analisa.io for TikTok)

\begin{tabular}{ccccc}
\hline $\begin{array}{c}\text { Nama Akun } \\
\text { TikTok }\end{array}$ & Nama Asli & $\begin{array}{c}\text { Total } \\
\text { followerss }\end{array}$ & $\begin{array}{c}\text { Total } \\
\text { views }\end{array}$ & $\begin{array}{c}\text { Total } \\
\text { likes }\end{array}$ \\
\hline @ basyasman00 & $\begin{array}{c}\text { Husein } \\
\text { Basyasman }\end{array}$ & 3.100 .000 & 2.137 .100 & 555.737 \\
\hline @indahrama_ & $\begin{array}{c}\text { Indah } \\
\text { Ramadani }\end{array}$ & 1.100 .000 & 3.912 .055 & 861.485 \\
\hline @ zahidsamosir & $\begin{array}{c}\text { Zahid } \\
\text { Samosir }\end{array}$ & 641.400 & 4.497 .200 & 876.502 \\
\hline @ yennarahman & $\begin{array}{c}\text { Yenna } \\
\text { Rahman }\end{array}$ & 382.600 & 1.403 .400 & 114.892 \\
\hline @ Shernaaa & Nifkisyah & 293.500 & 225.400 & 50.360
\end{tabular}

Tabel 2. merupakan hasil penelusuran dari 5 content creator berkaitan dengan konten dakwah yang sampai bulan Mei 2021 tergolong eksis dilihat dari konsistensi engagement di social media tracker analisa.io. Melihat seluruh hasil unggahan dari setiap content creator. Kemudian dipilih satu per satu dari setiap konten yang diunggah yaitu dalam format video. Semua konten, masing-masing memiliki pengelolaan yang berbeda sebagai pembanding agar selalu diingat oleh pengikutnya Ciri khas yang dimaksud adalah berupa ajakan, persuasi, menghibur, mengedukasi, mengkampanyekan dan sebagainya, dilihat dari caption/tulisan/mini blog, video melalui analisis isi dan menarik sintesa/simpulan terkait teori dan konsep yang digunakan pada penelitian.

Salah satu temuan yang menarik disini bahwa semua content creator berusaha sebaik mungkin dalam menjalin engagement dengan followerss-nya salah satunya yaitu dengan menganggap mereka ada melalui terusan konten yang dibuat berdasarkan komentar dari netijen. Salah satu diantaranya yang paling konsisten dalam menjawab komentar dengan konten video yaitu contentcreator@shernaaa.

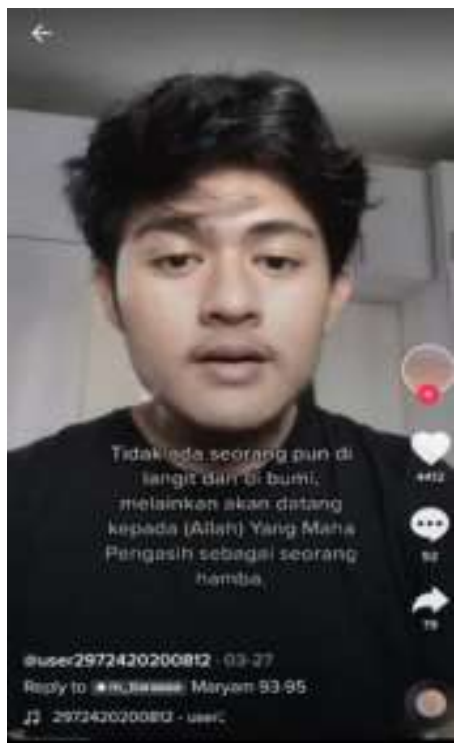

Gambar 2. Konten video dakwah unggahan @ shernaaa

Salah satu unggahan@shernaaa merupakan konten video yang diilhami dari komentar netijen pada video sebelumnya. Dengan cara ini juga dapat membantu 
konsistensi para content creator dakwah dalam perihal menjaga konsistensi pembuatan konten. Karena pada dasarnya salah satu indikator dalam meraih engagement dengan sesama pengguna media sosial adalah presence atau kehadiran, sehingga penting untuk menjaga konsistensi dalam tetap mengunggah konten di media sosial. Terbukti dalam konsistensi postingan-nya, @shernaaa mengunggah konten video dakwah dengan rata-rata 36 video/ bulan.

Pada kolom komentar terdapat $4 \mathrm{~K}+$ komentar menyukai foto tersebut dan sebagian besar terpancing untuk turut berkomentar berupa permintaan untuk@shernaaa mencoba membacakan ayat-ayat al-qur'an yang lain. Tidak hanya itu, dengan kehadiran konten tersebut juga dapat membangun kesadaran kepada pengguna akun lainnya untuk mau belajar membaca al-qur'an hingga menginspirasi pengguna TikTok untuk dapat berkontribusi membuat konten dengan tema yang serupa dengannya.

@ shernaaa bahkan sama sekali tidak mencantumkan hashtag dalam caption di tiap content-nya, hal ini menunjukan konten video yang Ia unggah secara keseluruhan mengandalkan dari substansi dan materi yang Ia bahas yaitu mayoritas pembacaan ayat-ayat alqur'an yang Ia kuasai berdasarkan pada permintaan pengikutnya di kolom komentar.

Kaitannya dengan ilmu Fikih terdapat juga contentcreator @basyasman00 dengan rata-rata unggahan 90 video/bulan. Konten video yang ia buat syarat akan kaidah-kaidah keislaman yang membahas tentang hal-hal yang seharusnya dan tidak seharusnya dilakukan oleh seorang muslim dengan melihat fenomenafenomena yang sedang tren banyak dibahas di media sosial.

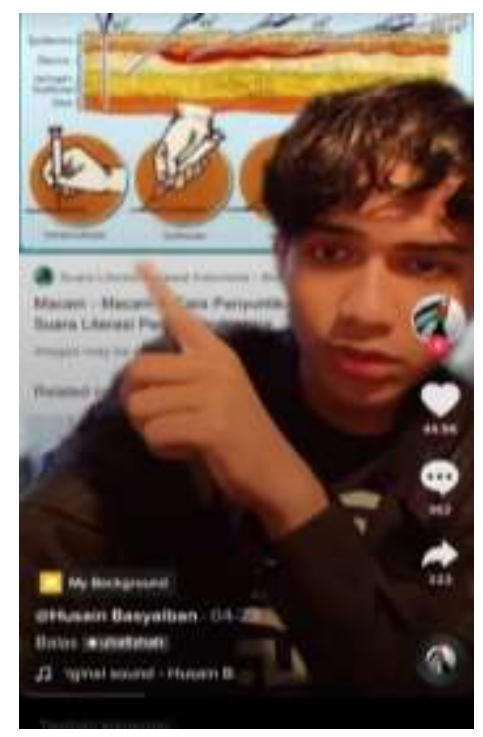

Gambar 3. Konten video @basyasman00

Konten video di atas merupakan salah satu pembahasan terkait keberadaan vaksin yang memang baru-baru ini dilaksanakan di Indonesia dan ada sebagaian masyarakat muslim mempertanyakan tentang efek vaksin terhadap muslim yang berpuasa, apakah membatalkan atau tidak?. @basyasman00 selalu merespon segala pembahasan di kontennya dengan kredibel sesuai dengan ilmu yang di Ia pelajari dari sudut pandang ulama. Sehingga apa yang Ia sampaikan sangat rasional hal ini juga dapat memberikan impact positif terhadap engagement pengikutnya untuk dapat menggali imu keislaman lainnya melalui konten video di akun TikTok@basyasman00. Seperti halnya yang 
disampaikan oleh (Ivan et al, 2020) menunjukan bahwa terkait dengan teori keterlibatan sosial bahwa kredibilitas konten adalah salah satu hasil dari keterlibatan pengguna di media sosial, dimana pengguna media sosial akan lebih tertarik utamanya pada konten-konten yang memiliki kredibilitas yang tinggi. Apalagi yang disampaikan adalah terkait dengan keagamaan, maka perlu juga pengguna TikTok untuk bertabayun.

Berbeda dengan teknik penyampaian pada konten@basyasman00 dan@shernaa, conten creator@indahrama_justru cukup membuat video dengan mecantumkan CTA (Call to Action) dengan diiringi musik-musik yang tren di TikTok. Dimana, dengan menyisipkan tren musik yang sering muncul di FYP (For Your Page) TikTok akan membuat konten yang dibuat menjadi mudah untuk masuk FYP (For Your Page).

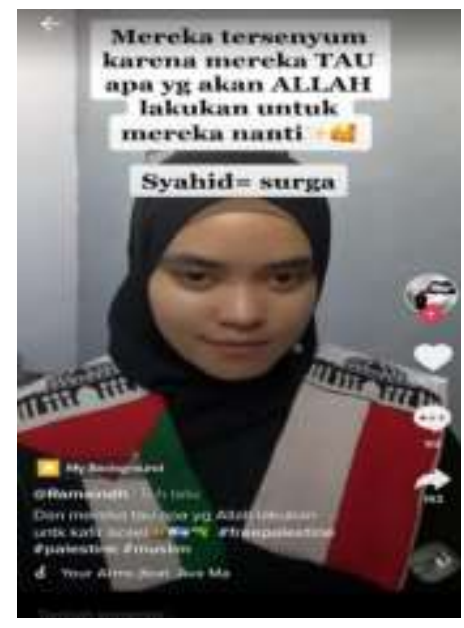

Gambar 4. Konten video @indahrama_

Hal ini dapat digunakan sebagai salah satu cara dalam penyampaian dakwah diikuti dengan
CTA yang ringan dan relatable dengan para pengguna di TikTok diharapkan akan mudah dipahami dan meraih engagement yang baik. Hingga kini@indahrama_konsesisten dengan rata-rata 63 post/ video dengan analisis 3 hashtag yang paling sering Ia gunakan antara lain: \#samasamabelajar \#fyp dan \#muslim.

Kemudian, menelusuri akun media sosial TikTokmilik@zahidsamosir dengan memulai aktivitas membuat konten di media sosial TikTok sejak tanggal 8 Juni 2020, dimana masih di awal pandemi Covid-19, selama massa PSBB @zahidsamosir konsisten mengunggah konten berformat video dengan menggunakan backgroundmusic yang sedang tren, isi teks singkat mengenai isu yang ia bahas dan rekaman dirinya dalam menjelaskan isu tersebut, dengan demikian konten yang Ia buat mampu menggerakan para pengikutnya di media sosial TikTok. Kini hampir seluruh video yang Ia buat selalu tampil di 'For Your Page' Menurut (Korich, 2016) media sosial TikTok terutama digunakan oleh kelompok audiens yang lebih muda dan remaja untuk menciptakan kesenangan, menarik secara visual dan kreatif. 


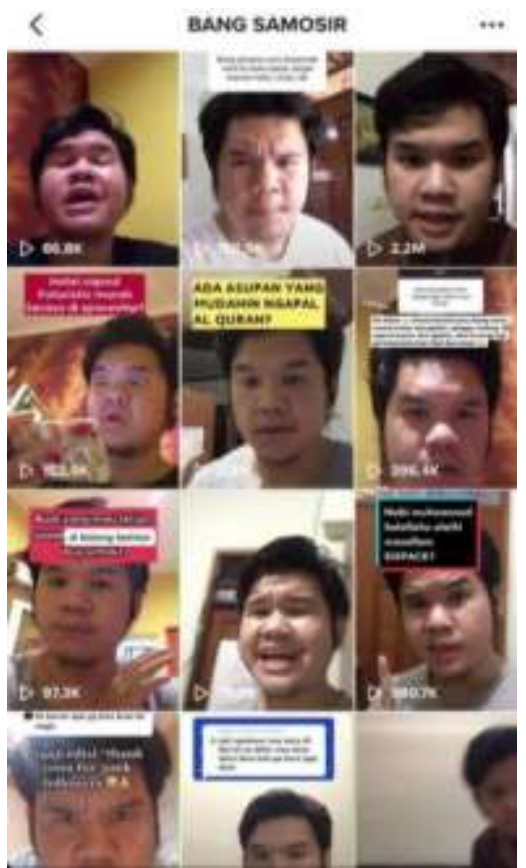

Gambar 5. Konten Video @zahidsamosir

Penggemar akun TikTok

@ zahidsamosir yang mayoritas adalah milenials dan dengan konten video yang unik dan sangat merepresentasikan kehidupan para penggemarnya, hal ini membuat materi dakwah tersampaikan dengan baik dan dapat diterima oleh pengikutnya di TikTok, materi dakwah yang disampaikan tak terlepas dari kajian islami yang diintregasikan dengan isu-isu terkini yang membuat konten menjadi relevan dengan kehidupan mereka. Banyak respon positif dapat dilihat di kolom komentar tiap postingannya. Hal inilah yang kemudian memotivasi @zahidsamosir salah satunya untuk menjaga konsistensi unggahan videonya hingga 30 video/bulan dengan penggunaan 3 hashtag \#stitch \#tiqtoqiah \#jalanyangkupilih.

Media sosial TikTok juga memiliki pembeda dibandingkan media sosial lain, dimana pengguna TikTok dapat melakukan live streaming jika telah meraih paling sedikit 1000 followerss. Hal inilah yang kemudian dimanfaatkan oleh contentcreator @yennarahman, dalam rangka menjaga koneksi dengan followerss-nya, @yennarahman tergolong contentcreator dakwah yang konsisten mengadakan live dengan para followerss-nya agar dapat saling sharing secara langsung tentang ilmu keislaman. Materi dakwah yang Ia sampaikan tidak sebatas hanya opini saja namun juga disertai dengan kebenarannya dalam menyertakan sepenggal ayat al-qur'an yang relevan dengan materi yang sedang dibahas. Dalam 1 bulan Ia berhasil konsisten mengunggah 15 video/bulan.

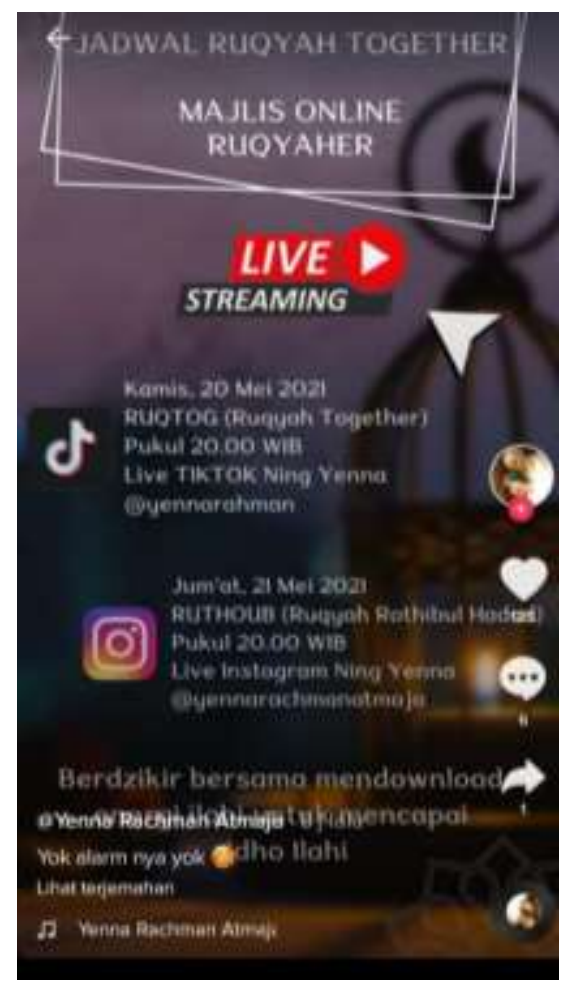

Gambar 5. Konten video @yennarahman 
Keuntungan lainnya dalam bermedia sosial adalah dapat saling terkoneksi dengan media sosial lain, selain melakukan live di akun TikTok-nya, @yennarahman juga tak jarang melakukan live streaming melalui media sosial lain yang kemudian ia promosikan melalui TikTok, mayoritas konten yang Ia buat kini muncul di FYP (For Your Page) para pengguna, hal inilah yang juga memudahkan Ia dalam menjaring peserta dalam mengikuti live dakwah streaming yang diadakan.

Dari pembahasan di atas, media sosial TikTok menjadi salah satu media yang diminati selama pandemi Covid-19 karena content creator dimudahkan dalam membuat konten berformat video tanpa harus ada proses editing yang lama, intensitas video-video keagamaan dapat diunggah lebih banyak ditambah ketersediaan waktu luang selama PSBB dan adanya rekomendasi oleh TikTok untuk ditonton oleh pengguna membuat para pengguna semakin sering terpapar materi dakwah, tausiyah, motivasi, hafalan ayat-ayat Al Qur'an dengan total penonton hingga jutaan.

Respon pengguna media sosial TikTok pada konten dakwah melalui media sosial TikTok milik content creator secara umum menunjukan respon yang positif dilihat dari engagement serta penambahan jumlah followers dan penonton di akun TikTok. Hal ini mencirikan keberhasilan content creator dalam membangun reputasi yang baik terhadap akun media sosialnya (Kapoor et al., 2018). tren dakwah digital melalui media sosial TikTok menunjukan kedinamisan pada perkembangan dakwah, masyarakat modern di tengah kemajuan teknologi komunikasi akan menuntut penggunaan media baru lainnya sebagai tren dakwah digital yang relevan dan sesuai kebutuhannya.

\section{Simpulan dan Saran}

Penelusuran konten dakwah melalui content creator dalam sosial media TikTok memberikan pandangan, jawaban, maupun kebaruan yang didapat oleh para peneliti komunikasi sosial media, karena banyaknya relevansi terhadap implementasi komunikasi baru dalam sosial media, terutama pembentukan opini terhadap penggunaan TikTok sebagai media kontemporer untuk berdakwah. Beberapa akun merupakan representasi perlibatan dan antuasiasme content creator untuk berkontribusi dalam penyebaran ilmu keagamaan yang sesuai dengan kaidah keislaman melalui media baru yang secara teknis dapat dimaksimalkan dengan berbagai fitur yang ada di media sosial TikTok, respon pengikut, like, views, tagar, yang dapat membantu penyebaran konten dakwah yang lebih luas. Simpulan yang dapat ditarik dari penelitian ini adalah:

1. Perkembangan fitur dan kemudahan para pengguna di media sosial TikTok telah memberikan insight yang sangat baik, sesuai dengan preferensi pengguna TikTok untuk mendapatkan konten video dakwah maka media sosial TikTok dapat memenuhi 
kebutuhan tersebut dengan akurat, kemudahan aksesbilitas bagi pengguna sehingga dengan mudah membagikan video dakwah kepada pengguna yang lain termasuk antar sosial media, dan juga pemasaran TikTok yang unik yaitu fokus pada segmentasi konten sesuai minat penggunanya.

2. Sebagai media populer maka TikTok menjadi rujukan media yang ideal dalam melakukan dakwah digital di media sosial oleh para content creator, dengan kajian islami yang dibahas secara ringan dibalut dengan isu-isu terkini serta tidak terkesan menggurui. Dari banyak respond positif dari para pengguna TikTok pada konten dakwah dapat menjadi motivasi bagi content creator untuk konsisten menyebarkan ilmu keagamaan melalui dakwah yang kreatif. Kemudahan dalam proses pembuatan video di TikTok juga menjadi kelebihan tersendiri bagi content creator untuk konsisten membuat video-video dakwah terutama untuk mengisi waktu luang selama pandemi Covid-19.

\section{Ucapan Terima Kasih}

Penulis mengucapkan terima kasih kepada semua pihak yang membantu proses terselesaikannya penelitian. Penulis mengucapkan terima kasih kepada kedua orang tua, dan adik serta keluarga besar Jurusan Komunikasi Penyiaran Islam, Fakultas
Ushuluddin, Adab, dan Dakwah, IAIN Syekh Nurjati Cirebon.

\section{Daftar Pustaka}

Amin, Samsul Munir. 2008. Ilmu Dakwah. Jakarta: Amzah.

Annur, Cindy Mutia. 2020. "Pengguna Tiktok Naik 20\% Selama Pandemi, Terbanyak Konten Edukasi.” Katadata.Co.Id. https://katadata.co.id/ekarina/digital/5ec22 45aa8bc7/pengguna-tiktok-naik-20selama-pandemi-terbanyak-kontenedukasi.

Ayuningtyas, Riska Sepriani. 2020. "Resistensi Jobi Adhiguna Atas Wacana Diskursus Masyarakat Mengenai Gender (Analisis Isi Kualitatif Video Blog Jovi Adhiguna Hunter Pada Channel Youtube)." Universitas Muhammadiyah Surakarta.

Aziz, M. A. 2019. Ilmu Dakwah. Jakarta: Prenada Media.

Budiansyah, Arif. 2020. "Deretan Fitur TikTok Yang Wajib Kamu Coba, Simak Nih!” CNBC Indonesia. https://www.cnbcindonesia.com/tech/2020 0221163748-37-139654/deretan-fitur-

tiktok-yang-wajib-kamu-coba-simak-nih. daon001. 2018. "Ini Penyebab Kominfo Putuskan Blokir Tik Tok." Kominfo. https://kominfo.go.id/content/detail/13331/ ini-penyebab-kominfo-putuskan-blokir-tiktok/0/sorotan_media.

Fahrurrozi. 2017. Model-Model Dakwah Di Era Kontemporer. Mataram: LP2M UIN 
Mataram.

Frick, T. 2013. Return On engagement: content, Strategy And Design Techniques For Digital Marketing. England: Taylor \& Francis.

Habibi, M. 2018. “Optimalisasi Dakwah Melalui Media Sosial Di Era milenial." Al-Hikmah: Jurnal Dakwah 12 (1): 101-16.

Haryatmoko. 2011. Etika Komunikasi. Yogyakarta: Kanisius.

Hayes, Clare, Katherine Stott, Katie J Lamb, and Glenn A Hurst. 2020. “"Making Every Second Count': Utilizing TikTok and Systems Thinking to Facilitate Scientific Public engagement and Contextualization of Chemistry at Home." Journal of Chemical Education 97 (10). American Chemical Society: 3858-66. doi:10.1021/acs.jchemed.0c00511.

Hikmawati, Sholihatul Atik, and Luluk Farida. 2021. "Pemanfaatan Media Tik Tok Sebagai Media Dakwah Bagi Dosen IAI Sunan Kalijogo Malang." AL-ITTISHOL: Jurnal Komunikasi Dan Penyiaran Islam 2 (1).

Indrawan, Jerry, Efriza, and Anwar Ilmar. 2020. "Kehadiran Media Baru (new media) Dalam Proses Komunikasi Politik." Medium: Jurnal Ilmiah Fakultas Ilmu Komunikasi Universitas Islam Riau 8 (1). Jailani. 2020. “Optimalisasi Dakwah Digital Bagi Kaum milenial." Terbuireng.Online. https://tebuireng.online/optimalisasidakwah-digital-bagi-kaum-mileniall.
Kapoor, K. K., K. Tamilmani, N. P. Rana, P. Patil, Y. K. Dwivedi, and S. Nerur. 2018. "Advances In Social Media Research: Past, Present And Future." Information Systems Frontiers 20 (3): 531-58.

Kholilie, Gus Muhammad Ismael Al. 2020. "Dakwah Tiktok." Jaringansantri.Com. https://jaringansantri.com/dakwah-tiktok/.

Kumparan. 2020. "Ini Asal Muasal TikTok Yang Kini Mendunia.” Kumparan.Com. https://kumparan.com/berita-hari-ini/iniasal-muasal-tiktok-yang-kini-mendunia1ss18QadAEN\#: :text=Berasal dari Aplikasi Douyin\&text=Pada September 2016\%2C perusahaan asal,aplikasi video pendek bernama Douyin.\&text=Akibat meroketnya popularitas\%2C Douyin melakukan,yang lebih eyecatching\%2C yakni TikTok.

Mahanani, P. A. 2015. "Relasi Facebook Dengan Budaya Pop Dalam Perspektif Cultural Studies.” Dialogia 13 (1): 79-88.

Mayring, Philip. 2019. "Qualitative content Analysis Demarcation, Varieties, and Development." Journal Forum Qualitative Social Research 20 (3): 63.

Muhaemin, E. 2017. "Dakwah Digital Akademisi Dakwah." Ilmu Dakwah: Academic Journal for Homiletic Studies 11 (2): 341-56. doi:https://doi.org/10.15575/idajhs.v11i2.1 906.

Norhabiba, Fitri, and Sukma Ari Ragil Putri. 2018. "Hubungan Intensitas Akses Media 
Baru Dan Kualitas Interaksi Lingkungan

Sekitar Pada Mahasiswa Untag Surabaya.”

Interaksi: Jurnal Ilmu Komunikasi 7 (1):

8-15.

doi:https://doi.org/10.14710/interaksi.7.1.8

-15 .

Pardianto, P. 2013. "Meneguhkan Dakwah Melalui new media." Jurnal Komunikasi Islam 3 (1).

Qadaruddin, M. 2019. "Strategi Dakwah Dalam Merawat Pluralitas Di Kalangan Remaja.” Strategi Dakwah Dalam Merawat Pluralitas Di Kalangan Remaja 19 (2): 177-98.

Rakhmayanti, Intan. 2020. "Pengguna TikTok DiIndonesia Didominasi Generasi Z Dan Y.” Tekno.Sindonews.Com. https://tekno.sindonews.com/berita/152369 2/207/pengguna-tiktok-di-indonesiadidominasi-generasi-z-dan-y.

Rustandi, R., and S Sahidin. 2019. "Analisis Historis Manajemen Dakwah Rosulullah Saw Dalam Piagam Madinah.” Tamaddun: Jurnal Sejarah Dan Kebudayaan Islam 7 (2): 362-87. doi:10.24235/tamaddun.v7i2.5503.

Wibowo, A. 2019. "Penggunaan Media Sosial Sebagai tren Media Dakwah Pendidikan Islam Di Era Digital.” Jurnal Islam Nusantara 3 (2): 339-56.

Widyananda, Rakha Fahreza. 2020. "10 Macam Media Sosial Yang Paling Sering Digunakan Oleh Orang Indonesia." Merdeka.Com. https://www.merdeka.com/jatim/10macam-media-sosial-yang-paling-seringdigunakan-oleh-orang-indonesia-kln.html. 
Halaman ini sengaja dikosongkan untuk kepentingan tata letak

Orasi: Jurnal Dakwah dan Komunikasi | Volume 12, No. 1, Juli 2021 